\title{
The influence of a PHI-5-loaded silicone membrane, on cutaneous wound healing in vivo
}

\author{
M. van Rossum · D. P. P. Vooijs · X. F. Walboomers • \\ M. J. Hoekstra $\cdot$ P. H. M. Spauwen · J. A. Jansen
}

Received: 18 April 2005/Accepted: 26 January 2006/Published online: 27 March 2007

(C) Springer Science+Business Media, LLC 2007

\begin{abstract}
This study investigated whether a novel ionogenic substance, containing amongst others zinc and rubidium (PHI-5; Dermagenics Inc, Memphis, TN, USA), could improve the healing of full-thickness skin wounds. Uniform wounds were created on the right flank of guinea pigs. Micro-grooved silicone rubber membranes, containing 0 (controls), 1.25, 5.00, or $10.00 \mu \mathrm{g}$ PHI-5, were sutured onto this wound. Standardized digital wound photographs were made after 1,3 , and 6 weeks. Also, wound biopsies were taken after 3 and 6 weeks for histological and histomorphometrical evaluation. For all study groups, 6 animals were used. Analysis of the 1-week digital photographs showed that the surface area of the wounds decreased significantly, with an increasing PHI-5 concentration. No other differences were found in the wound photographs. Also, no differences were measured in histomorphometry at 3 and 6 weeks. Concluding, in our study model a single application of PHI-5 did have a significant positive influence on initial wound healing.
\end{abstract}

M. van Rossum - D. P. P. Vooijs · X. F. Walboomers .

J. A. Jansen ( $\square)$

Department of Periodontology \& Biomaterials, Radboud

University Nijmegen Medical Centre, THK 309 PB,

P. O. Box 9101, 6500 HB Nijmegen, The Netherlands

e-mail: j.jansen@dent.umcn.nl

D. P. P. Vooijs · P. H. M. Spauwen

Department of Plastic \& Reconstructive Surgery, Radboud

University Nijmegen Medical Centre, Nijmegen,

The Netherlands

M. J. Hoekstra

Burns Research Institute, Beverwijk, The Netherlands

\section{Introduction}

Disturbances in cutaneous wound healing are a major clinical issue. Especially chronic wounds, like pressure sores, and diabetic and venous ulcers, are expected to form a growing problem, because of the ageing of our population, and an increase in prevalence of diabetes and level of disability. Systemic risk factors for developing and sustaining a chronic wound can be corrected to some extent. Potential treatments have focused on local aspects, for instance by wound debridement, pressure regulation, application of growth factors, the use of (bio-engineered) skin equivalents, and specific wound dressings [1]. Despite present therapeutical options, healing of these wounds takes much time, effort and money, causing a burden on national health care.

PHI-5 (Dermagenics Inc, Memphis, TN, USA) is a novel formulation containing zinc and rubidium ions, which is developed for treatment of chronic wounds [2]. Commercially, PHI-5 is available as an impregnated wound dressing material (Dermax $\left.{ }^{\circledR}\right)$. The ion formula in PHI-5 is based on analysis of red oak bark extract, a material traditionally employed for its positive effect on wound healing. It has been shown that PHI-5 has a positive influence on wound healing, when applied in chronic wounds that were not responding to conventional therapeutical interventions [3]. Various authors already described an imbalance of matrix metalloproteinases (MMPs), and of MMP inhibitors (TIMPs), in chronic wound tissue and fluid [4-9]. It is assumed that PHI-5 has the capability to correct such imbalance between MMPs and TIMPs. Previously, many studies have shown comparable inhibition of several proteinases by zinc and other divalent metal ions (copper, cadmium, nickel, calcium) from a variety of chemical and organic sources [10-17]. 
Nevertheless, studies on PHI-5 have only been performed on human patients with chronic wounds. To date, no standardized (animal) experiments have been published in which the effect of PHI-5 was compared to non-treated control groups. Therefore, for our current study, the efficacy of PHI-5 in a standardized animal model was investigated. Also, different concentrations have to be regarded, as no optimal dose for PHI-5 has been described yet. We hypothesize that microtextured silicone wound covers loaded with PHI-5 can improve wound healing, when placed in a standardized full-thickness skin wound in vivo. Guinea pigs were selected as the experimental animal based on their skin structure, which is close to human skin [18]. The efficacy of the study design was already proven in an earlier comparable study [19].

\section{Materials and methods}

\section{Substrates with PHI-5}

Medical-grade silicone rubber (polydimethylsiloxane, NuSil MED-4211, NuSil Technology, CA, USA) was mixed as prescribed. To obtain a single-sided microtexture, the mixture was cast on a silicon template, containing micro-grooves with a groove depth of $1.0 \mu \mathrm{m}$ and a ridgeand groove-width of $10.0 \mu \mathrm{m}$ (C2V, Enschede, the Netherlands). After polymerisation, coin-shaped substrates of $20 \mathrm{~mm}$ diameter were cut from the produced sheets. Substrates were washed in $10 \%$ liquinox solution (Alconox, New York, NY, USA), cleaned ultrasonically, and rinsed thoroughly in reverse osmosis water (MilliQ, Millipore Corp, Bedford, MA, USA). Subsequently, they were washed in $70 \%$ and $100 \%$ ethanol and dried to air. The membranes were autoclaved for sterilisation at $121{ }^{\circ} \mathrm{C}$ for $15 \mathrm{~min}$. A radio frequency glow discharge (RFGD; Argon, $5 \mathrm{~min}$ ) treatment was applied to remove surface fouling, and to hydrophilize the textured side. Finally, the membranes were loaded with aliquots of equal volume, containing 0, (controls), 1.25, 5.00 and $10.00 \mu \mathrm{g}$ of PHI-5, and lyophilized overnight.

\section{Animals}

The study protocol was approved by our University Animal Ethics Committee, all experiments were carried out according to the Dutch Experiments on Animal Act, and under appropriate licenses. Specified pathogen-free male young adult albino Hartley-derived guinea pigs were used, weighing approximately $620 \mathrm{~g}$. The animals were housed individually, and received chow and water ad libitum. For each study group per time period 6 guinea pigs were used.
Each animal had one wound on its right flank, covered with one of the silicone membranes.

\section{Application procedure}

Pre-operatively, the animals were shaved thoroughly. Surgery was performed under general inhalation anesthesia of $\mathrm{O}_{2}, \mathrm{~N}_{2} \mathrm{O}$, and isoflurane. Prior to creating the wound, local anesthesia was given by infiltration with lidocain $2 \%$ including adrenalin. The skin was scrubbed with iodine, and subsequently, standardized orientation points to measure wound contraction were created with tattooing ink, using fixed holes in a pre-made steel mold. The center of this mold contained a $20 \mathrm{~mm} \varnothing$ circular hole, used to mark the amount of tissue to be excised (Fig. 1A). Then, the circular full-thickness cutaneous wounds extending to the panniculus carnosus were created on the right flank of each guinea pig, using aseptic techniques. The silicone substrates were sutured onto the wound, with the side containing PHI-5 making contact with the wound (Fig. 1C). Subsequently, wounds were covered with semi-permeable polyurethane dressings (Tegaderm, 3M Co, Minneapolis, Mn, USA). One layer of dry sterile fine mesh gauze (Tendra Mesoft $5 \times 5 \mathrm{~cm}$, Mölnlycke, Göteborg, Sweden) was applied onto the Tegaderm, and the dressings were secured in place with two circular layers of surgical tape (Elastoplast-E $6 \mathrm{~cm}$, Beiersdorf, Spain). Special attention was paid to the design of the bandage. The outer layer of tape was also wrapped in front of the fore legs, thus preventing the guinea pigs to remove it by paw movement or chewing (Fig. 1D). After 1 week, the PHI-5 containing silicone membranes were removed. Thereafter, the bandages were reapplied.

After 3 or 6 weeks, animals were sacrificed by intracardial injection of a lethal dose of pentobarbital, after which the wound and all surrounding tissues were retrieved for histological and histomorphometrical analyses.

\section{Morphometrical evaluation of the wounds}

The method of evaluation was adapted from our previous publication [19]. Standardized digital wound photographs were taken on days 7, 21 and 42, using a digital camera on macro setting. Photographs were calibrated to distance with a ruler on each photograph, using Leica Qwin software (Leica Microsystems Imaging Solutions, Ltd, UK). Per photograph, two measurements were made (Fig. 2A-C); Wound Surface Area (WSA) and Reference Surface Area (RSA). These indicate the amount of wound closure, and the amount of wound contraction respectively. 
Fig. 1 Surgical procedure. (A) The surgical area was drawn onto the skin using a prefabricated steel mold. (B) Anaesthetized guinea pig with drawing on right flank. (C) Circular wound, $2 \mathrm{~cm} \varnothing$, after application of the silicone membrane. (D) Application of bandage
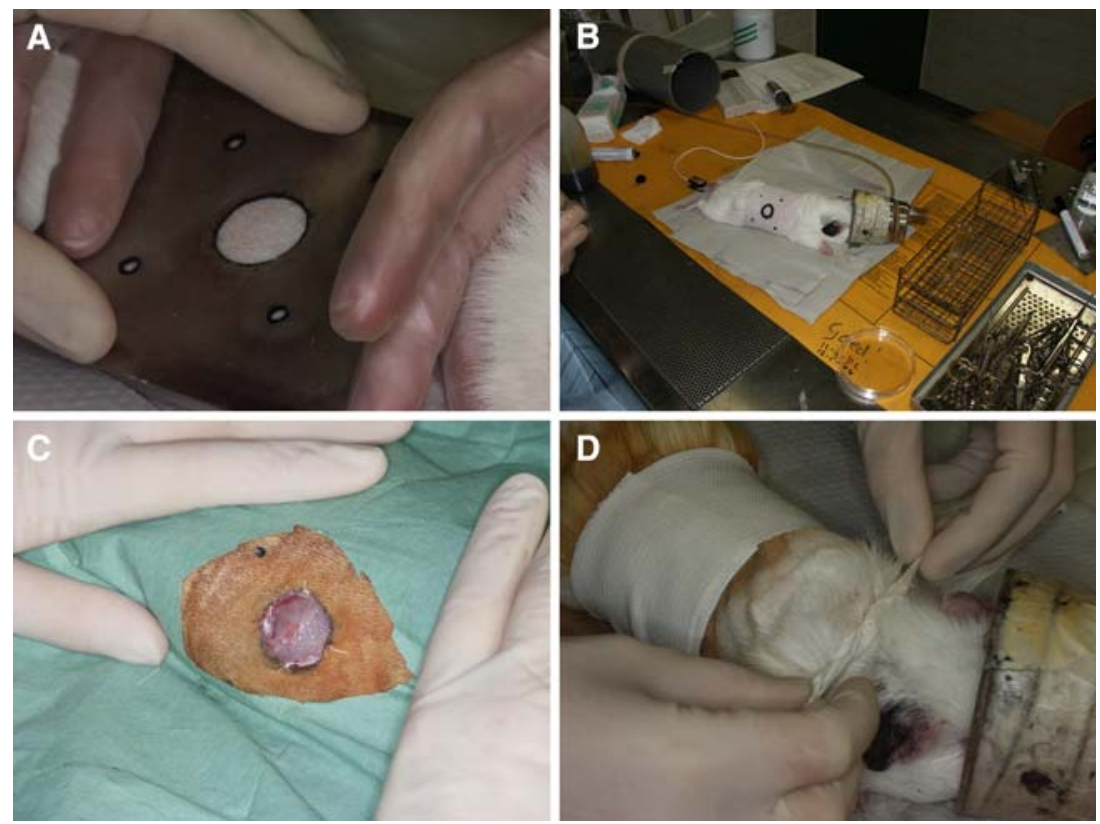

Histological evaluation techniques

After retrieval, the excised tissue was fixed in $4 \%$ buffered formaldehyde for $24 \mathrm{~h}$, dehydrated in a series of ethanol, and embedded in paraffin. Thereafter, $6 \mu \mathrm{m}$ sections were cut using a Leica RM 2165 Microtome. Every 25th section was collected and stained with haematoxilin and eosin (Merck, Darmstadt, Germany).

\section{Histomorphometry}

Computer-based image analysis of re-epithelialisation, wound area, and granulation tissue was performed on histological images. Per wound three histology sections, $150 \mu \mathrm{m}$ apart, were selected for evaluation. In the 3-week sections, three parameters were measured at pre-determined locations in the wound: length of the neo-epithelial layer, size of wound opening, and narrowest width of the granulation core (Fig. 3). In the 6-week sections, measurements were made in three layers of the superficial granulation tissue, thereafter calculating the mean length of the superficial granulation tissue. Also, the narrowest distance between hair follicles (representing the edges of the original skin tissue) on either side of the originally excised wound tissue, was measured (Fig. 4).
Fig. 2 Morphometrical

analysis of a wound at day 7 (A)

Wound, with calibration ruler.

(B) Wound Surface Area

(WSA). (C) Reference Surface Area (RSA)
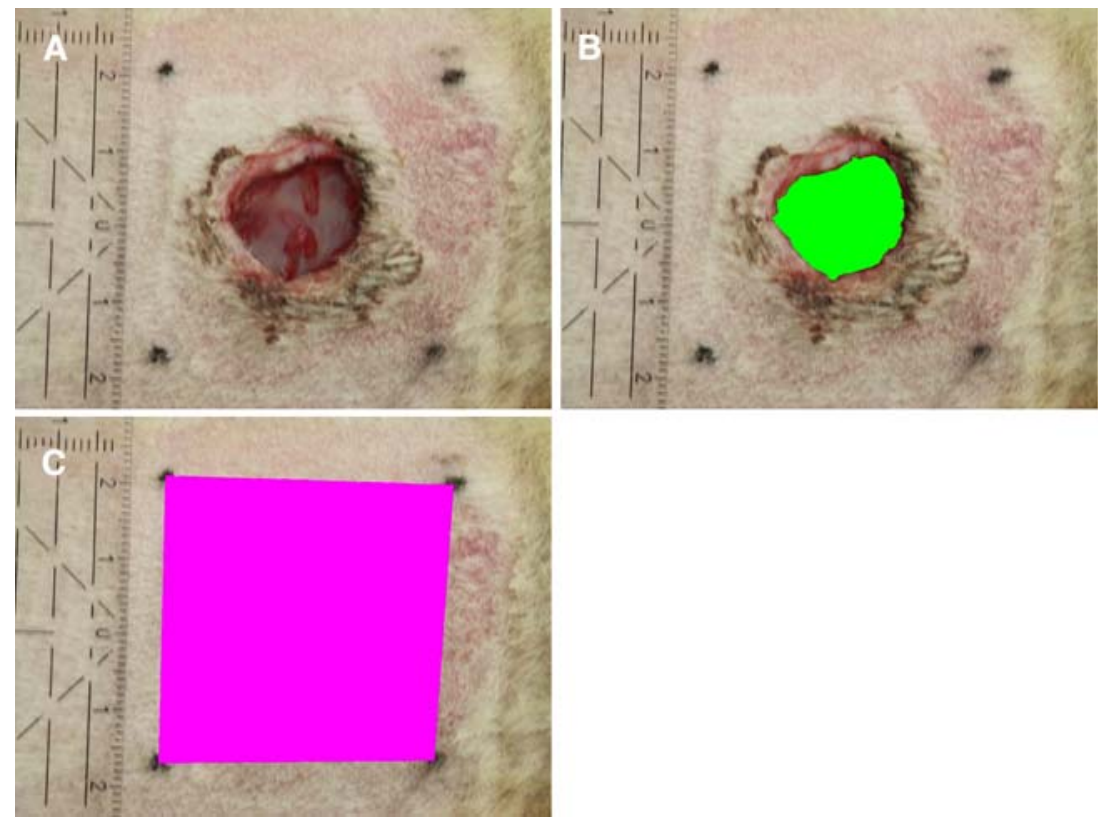


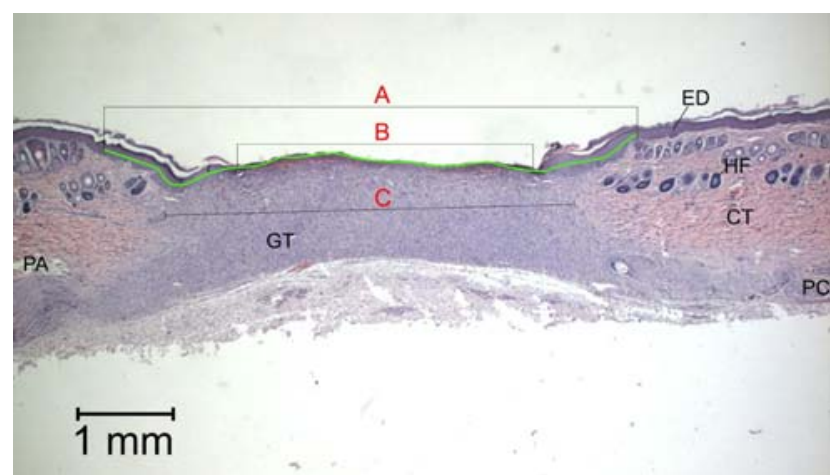

Fig. 3 Histomorphometrical measurements on a histological section, 3 weeks after surgery. $\mathrm{A}=$ length of neo-epithelium $\mathrm{B}=$ wound opening, $\mathrm{C}=$ width of granulation tissue $\mathrm{ED}=$ epidermis, $\mathrm{HF}=$ hair follicle, $\mathrm{CT}=$ connective tissue, $\mathrm{GT}=$ granulation tissue, $\mathrm{PC}=$ panniculus carnosus, $\mathrm{PA}=$ panniculus adiposus

Statistical analysis

The averages and standard deviations of data from the quantitative measurements were calculated. Then, data were compared with a one-way ANOVA and a Tukey post-hoc test, using InStat software (v3.05, GraphPad InStat software, GraphPad Inc.). A $P$ value below 0.05 was considered to be significant.

\section{Results}

\section{Clinical observation}

One guinea pig in the high concentration study group died day one post-operative of unknown cause. All other animals remained in good health throughout the experiment, and no wound infections were observed. Only three guinea

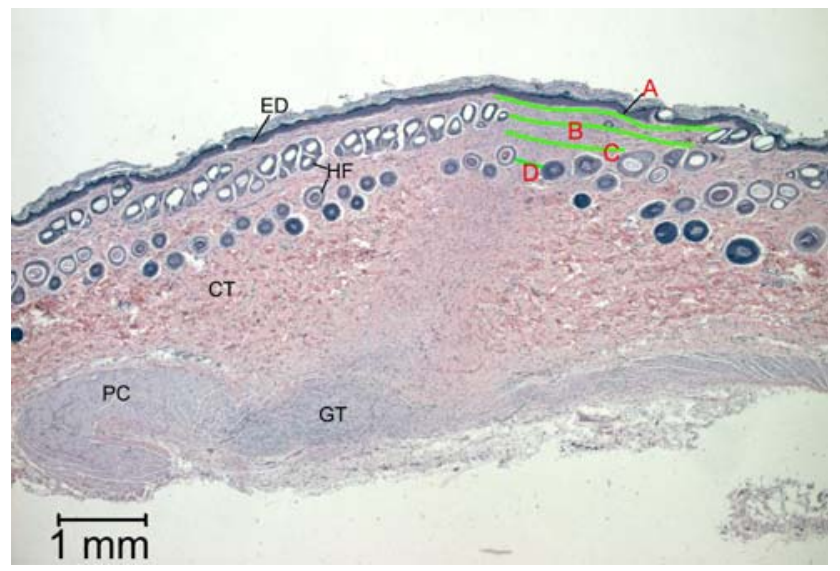

Fig. 4 Histomorphometrical measurements on a histological section, 6 weeks after surgery. Length of superficial granulation tissue is measured at three levels (A, B, C), as well as the narrowest distance between hair follicles (D) pigs managed to remove the bandage before the end of the study period.

After 1 week, in all groups it was observed that the wounds had not closed yet. After 3 weeks, the wounds were nearly closed or closed. After 6 weeks, all wounds were fully closed, resulting in an elongated scar, directed cranio-caudally (Fig. 5A-D). One of the animals showed wound closure in a dorsoventral direction. Therefore, this animal was excluded from histomorphometrical measurements.

\section{Wound photographs}

After 1 week, significant differences between study groups were measured for the WSA. Here, the control animals still had the largest wounds. Increase of the concentration of PHI-5 resulted in a decrease of the wound size. This difference was significant as tested by ANOVA. Tukey's post hoc test revealed a significant difference between the control group and the high concentration group. However, after 3 weeks, this difference was not found to persist. After 6 weeks, all wounds were closed, so that the WSA could not be measured (Fig. 6).

For measurement of the RSA, one animal of the low concentration group was excluded because of doubtful tattoo markings. In all experimental groups, the RSA could be found to expand (Fig. 7) over the study period. No significant differences between groups could be found on any experimental period measured.

\section{Histology}

Three weeks after surgery, the excised skin was replaced by a varying amount of granulation tissue, consisting of fibrinoid material and inflammatory cells (Fig. 8A-B, 9A-B). Of all excised wounds, two seemed still to have an intact panniculus carnosus. Re-epithelialisation was observed over the woundbed area, although only five wounds (all in the control and low concentration groups) were fully covered by an intact epithelium, containing a recognisable basal cell layer. When a defect of epithelial lining was still present, many superficial capillaries were seen, as well as thickening of the epithelium at the wound edges.

In all sections of the 6-week specimens, an intact keratinizing squamous epithelial lining was seen, which in some cases showed the start of rete peg formation (Fig. 10). Just below the epithelium, a varying amount of granulation tissue was present, becoming narrower at the level of the hair follicles and connective tissue. Even deeper in the sections, a broad area of granulation tissue was always predominantly present, in between both sides of the pre-existent panniculus carnosus. 
Fig. 5 Wound appearance. (A) Day 7, all wounds are still open. (B, C) Day 21, wounds are either (B) nearly or (C) fully closed. (D) Day 42, all wounds are closed, producing a linear craniocaudal scar
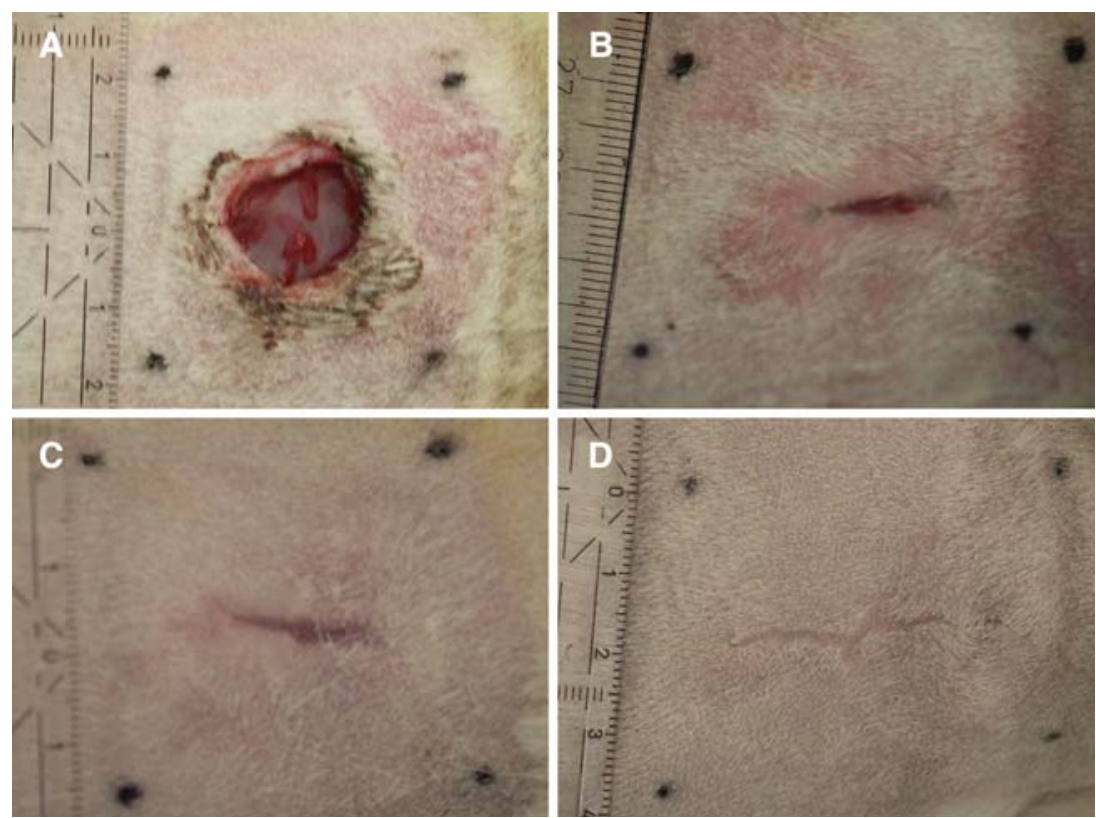

\section{Histomorphometry}

After 3 weeks, no significant differences were found among the experimental groups for the length of the wound opening, neo-epithelium, or granulation tissue (Table 1).

Also, in the 6-week groups, no significant differences in length of the superficial granulation tissue or distance between hair follicles were found (Table 2).

\section{Discussion}

An in vivo study was performed on the effect of PHI-5 on cutaneous wound healing in a guinea pig model. First, a standardized wound was created. Results showed a faster wound closure after 1 week, when $10.00 \mu \mathrm{g}$ of PHI-5 was

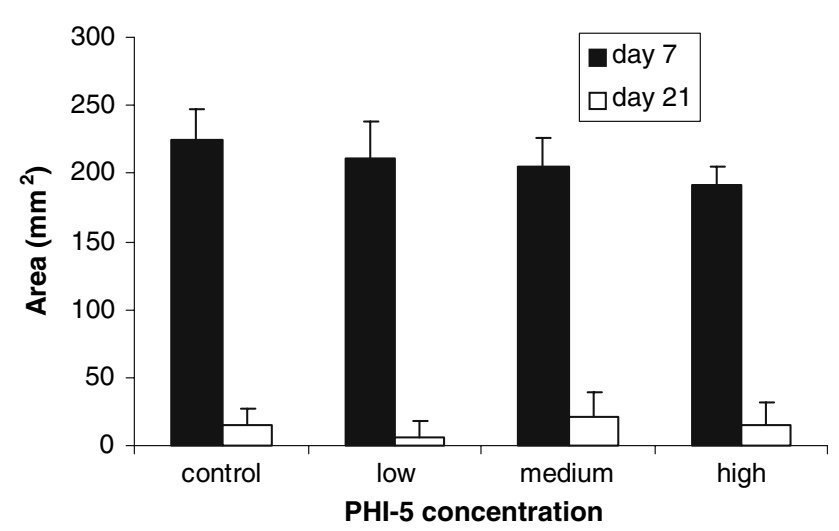

Fig. 6 Mean Wound Surface Area (WSA). Note that on day 7, with an increasing concentration of PHI-5, the wound surface was significantly smaller. Bars indicate SD applied. After 3 and 6 weeks however, no differences among study groups were found in any of the measurements.

Several remarks can be made about the study set-up. Guinea pigs were used, as these are a common animal model in research on cutaneous wound healing [18-25]. Although their skin structure is reported to be similar to human skin [18], some apparent differences still exist. Guinea pigs are loose-skinned, have a dense layer of body hair, a thin epidermis and dermis, a low amount of subcutaneous fat and their skin structure contains a panniculus carnosus $[18,26]$. Sullivan et al. state wound healing in such animals to be primary due to contraction. Therefore it will be definitely different from human cutaneous healing, where both re-epithelialisation and contraction play an

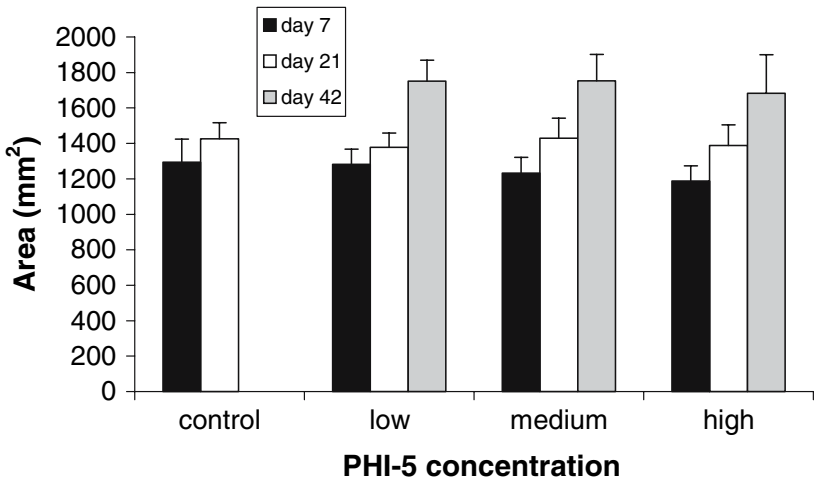

Fig. 7 Mean Reference Surface Area (RSA). In all groups, the RSA significantly expands over the days. Note also the trend of a smaller RSA with an increasing concentration of PHI-5 on day 7. These differences resemble those of the WSA, although here are not significant. Bars indicate SD 

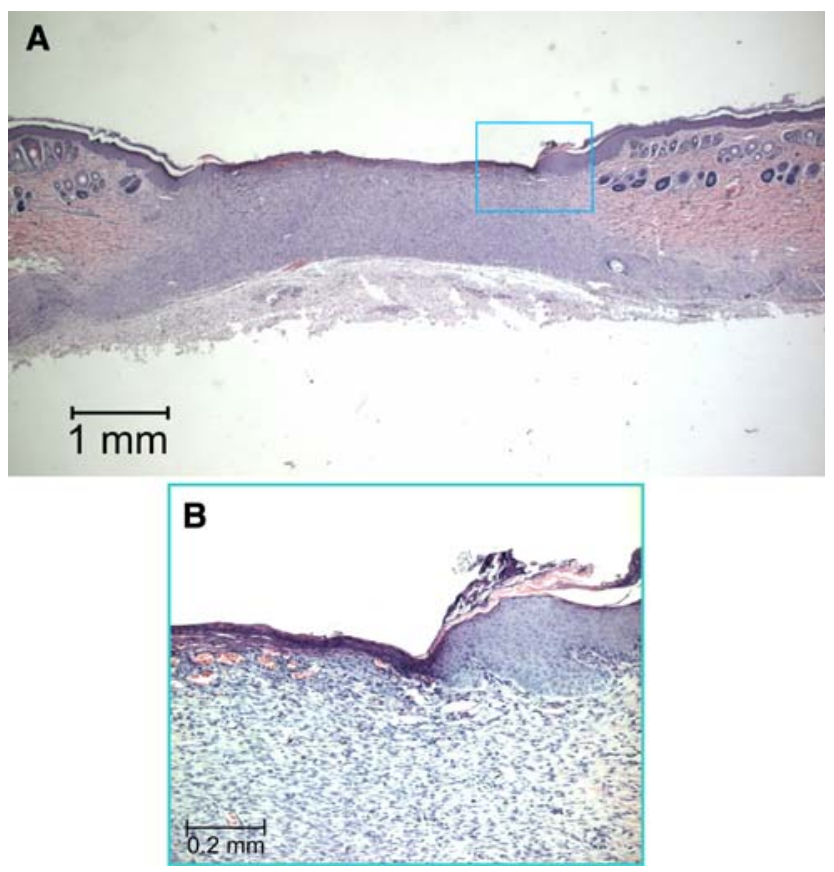

Fig. 8 Histological section, HE staining, 3 weeks after surgery. (A) A large epithelial defect is still present. (B) Higher magnification, note that the basal cell layer is deficient over the woundbed area

important role [26]. On the other hand, Gross and coworkers found no influence of looseness of skin on wound healing mechanisms [27]. In our study, we observed that
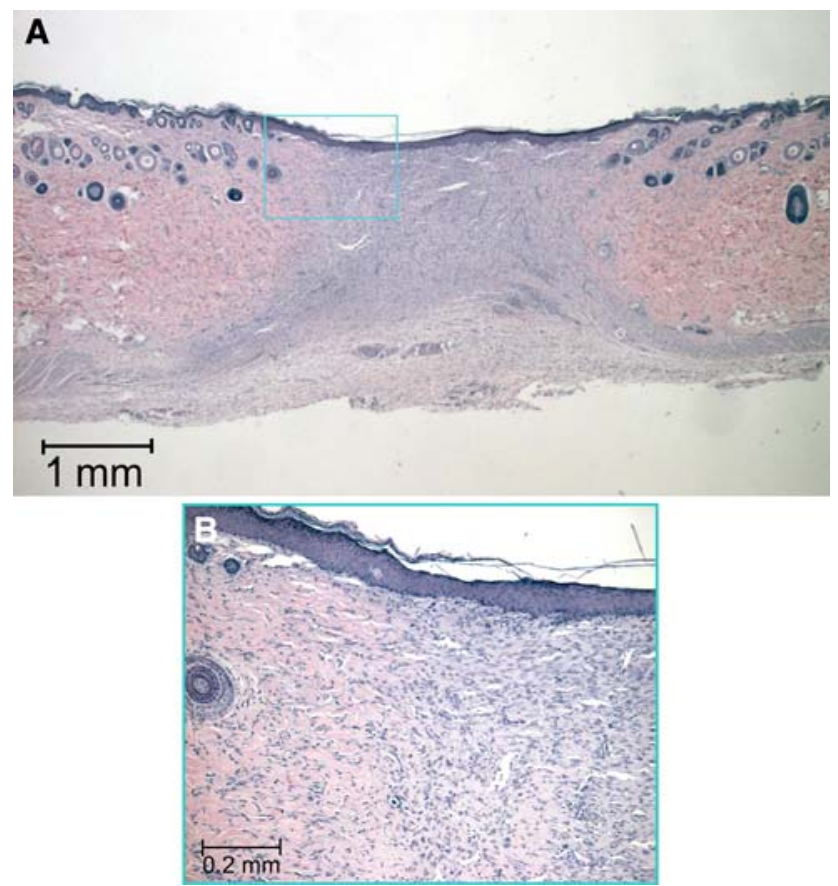

Fig. 9 Histological section, HE staining, 3 weeks after surgery. (A) The whole surgical wound area is covered by a new layer of epithelium (B) Higher magnification, note that the new epithelial layer contains an intact layer of basal cells
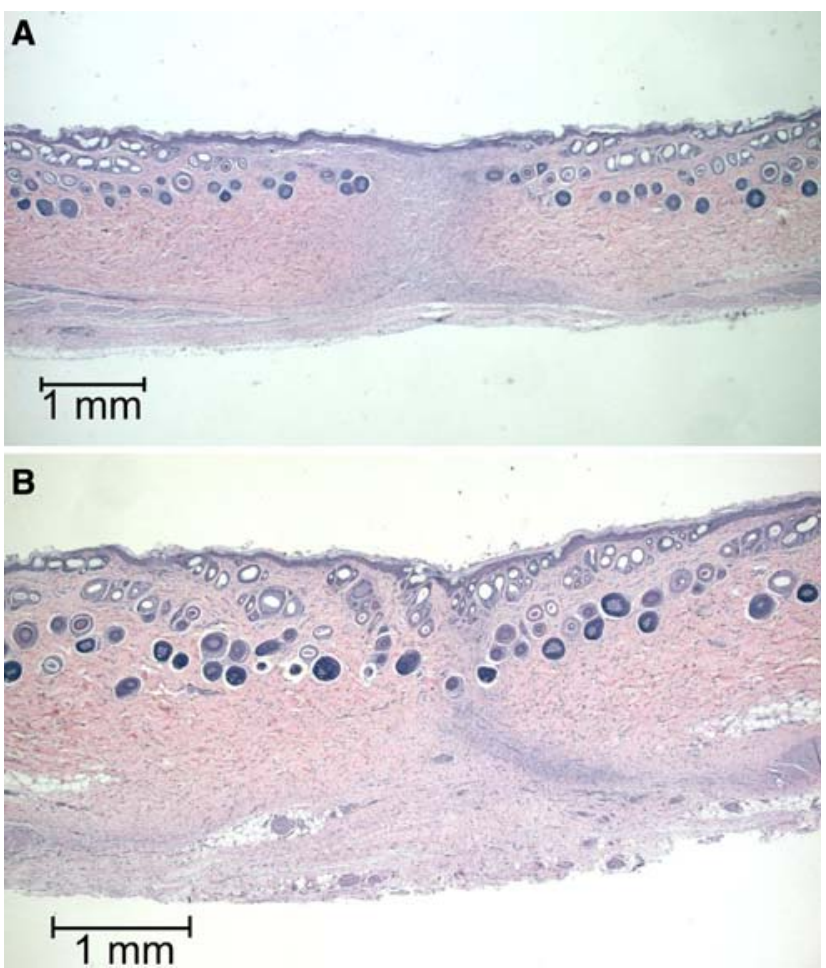

Fig. 10 Histological sections, HE staining, 6 weeks after surgery. (A) and (B) All sections are fully covered with epithelium, but contain varying amounts of granulation tissue

re-epithelialisation occured in the guinea pigs after 3 weeks. After 6 weeks of healing, the edges of the original skin tissue (containing hair follicles) were lying approximate to each other. This might indicate that eventual wound closure in guinea pig skin is due to contraction, and re-epithelialisation has just a temporary role in covering the original defect.

Besides the wound healing process, four other remarks should be made about the animal model. First, finding a bandage method for guinea pigs, which can stay secure for several weeks, has been challenging. With the method we applied here only three animals managed to remove their bandage. This very high success rate corroborates our earlier study [19]. Second, in efforts to minimize the use of laboratory animals, we adapted the study design from a previous study [19] where animals were sacrificed, and histology was processed at week 3 and 6 . No wound tissue was retrieved 1 week after surgery. In hindsight, this was an unfortunate decision since PHI-5 did exhibit an effect at week 1 . Third, the 'Reference Surface Area' is a parameter often used in measuring wound contraction. In this study, all areas increased throughout the experiment in each study group. Most probably, this parameter merely reflects the weight gain of the animals. For this reason, we conclude this measurement not to be appropriate for describing wound contraction in the experimental model. Finally, we 
Table 1 Average histomorphometrical measurements and standard deviations after 3 weeks $(\mathrm{mm})$

\begin{tabular}{lllll}
\hline & $\begin{array}{l}\text { Control } \\
(\mathrm{SD})\end{array}$ & $\begin{array}{l}\text { Low } \\
(\mathrm{SD})\end{array}$ & $\begin{array}{l}\text { Medium } \\
(\mathrm{SD})\end{array}$ & $\begin{array}{l}\text { High } \\
(\mathrm{SD})\end{array}$ \\
\hline Epithelial defect & $1.20(1.64)$ & $\begin{array}{c}1.17 \\
(1.61)\end{array}$ & $2.29(1.96)$ & $\begin{array}{c}2.99 \\
(1.09)\end{array}$ \\
$\begin{array}{c}\text { Granulation core } \\
\text { width }\end{array}$ & $2.48(1.02)$ & $\begin{array}{c}3.18 \\
(1.51)\end{array}$ & $2.85(0.72)$ & $\begin{array}{c}2.60 \\
(1.09)\end{array}$ \\
$\begin{array}{c}\text { Neo-epithelial } \\
\text { length }\end{array}$ & $4.94(2.06)$ & $\begin{array}{c}5.48 \\
(2.25)\end{array}$ & $5.99(1.68)$ & $\begin{array}{c}5.51 \\
(1.72)\end{array}$ \\
\hline
\end{tabular}

No significant differences between different concentration groups were found in width of epithelial defect, granulation core width, or length of neo-epithelium

Table 2 Average histomorphometrical measurements and standard deviations after 6 weeks $(\mathrm{mm})$

\begin{tabular}{llll}
\hline & Low (SD) & Medium (SD) & High (SD) \\
\hline Granulation width & $1.57(0.46)$ & $0.84(0.66)$ & $1.19(0.54)$ \\
Follicle distance & $1.35(0.87)$ & $0.59(0.54)$ & $0.60(0.46)$ \\
\hline
\end{tabular}

No significant differences between different concentration groups were found in width of superficial granulation tissue or in narrowest follicle distance among groups

have used an acute excisional wound model, although PHI-5 has originally been developed for treatment of chronic wounds. The rationale for this is that a chronic wound is uncommon in animals, and extraordinary measures (creating ischemia, denervation or diabetes) are required to attempt to reproduce authentic lesions in an animal model [28]. Moreover, all models still differ from human chronic wounds, which most often are multifactorial.

Like with the animal model, a specific annotation has to be made on the use of our delivery vehicle of PHI-5 into the wound area. It might be suggested, that suturing a silicone membrane onto the wound could serve as a stent keeping the wound open, and preventing wound contraction in the first week post operative. However, in a previous study no differences were seen between the control group wearing a silicone membrane, and a sham group having the wound left open [19].

Considering the measurements, after 1 week all wound photographs showed a decrease in WSA, for the higher PHI-5 concentrations. Especially, significant differences were found between the control group and the highest concentration group. This means, at least partially, the hypothesis can be maintained that microtextured polymeric membranes loaded with PHI-5 can improve wound healing, when placed in a full-thickness cutaneous wound in vivo. However, two weeks post operative, no significant differences between groups could be measured anymore. One plausible explanation for finding only short-term effects seems to be related to the release pattern of PHI-5. Earlier study results have shown that proteinaceous growth factors are released from microtextured surfaces, within $24 \mathrm{~h}$ in a burst-like manner [29]. Being a water-soluble ionic solution, PHI-5 is probably released even faster than proteins. In fact, clinicians usually are re-applying PHI-5-containing bandages daily. Thus, follow-up studies in the animal model should be designed to deliver multiple doses, or make use of an appropriate slow-release system. Next to the delivery mode, the efficacy of PHI- 5 could also be dependent on the dose. The greatest effect of PHI-5 was measured, when the high concentration of $10.00 \mu \mathrm{g}$ per wound was used. Even higher concentrations would have to be tested, to find the optimum level for treatment.

The first scope of this study was to prove that PHI-5 is effective in a standardized animal model. Although the underlying working mechanism of PHI-5 was not investigated, some knowledge exists on this subject. The expression of MMP-2 is higher in chronic wounds than in acute wounds [10, 14], and the role of MMP-2 in non-healing wounds is thought to be a pathological one [1, 4-7]. Previous literature postulates that PHI-5 corrects an imbalance of MMPs in the wound area, by lowering the release of MMP-2. On the contrary, other researchers also suggest a pivotal physiological role for MMP-2 in the re-epithelialisation of acute human wounds [30]. Downregulation of MMP-2 by PHI-5 has been stated based on biopsies from wounds treated with Dermax ${ }^{\circledR}$ [3]. The mechanism of inhibition is unknown, but might be a direct effect of PHI-5 on MMP-2 activity. Possibly, the metal ions in PHI-5 bind to the active part of the protease, preventing the enzyme to bind to its substrate. Alternatively, the ions could cause conformational changes, thereby lowering the catalytic function of the enzyme [17]. However, inhibition of MMP-2 can also theoretically be an indirect effect of PHI-5, due to a naturally occurring concentration decline of MMP-2 throughout the healing process.

Alternative working mechanisms have been stated by van den Berg et al. They showed that PHI-5 inhibited complement activation, and the production of reactive oxygen species by polymorphonuclear neutrophils. Both of these factors could also be contributing factors in the positive effect of PHI-5 on wound healing [31].

\section{Conclusion}

Concluding, we can say that PHI-5 has a positive influence on early cutaneous wound healing in a standardized animal model. The results seem to justify further studies using 
higher doses and sustained release systems loaded with PHI-5, and on elucidating its working mechanism.

Acknowledgements NWM van Dijk for technical assistance, Dermagenics Inc. for supplying the PHI-5 formulation. Supported by the Dutch Technology Foundation STW, grant \# NGN.4822.

\section{References}

1. K. G. HARDING, H. L. MORRIS and G. K. PATEL, BMJ 324 (2002) 160

2. Patent Dermagenics Europe B.V. Dressing material and dressings for the treatment of wounds. Madrid Registration No. 780930. 2002 Mar 12

3. R. B. KARIM, A. K. J. AHMED, B. L. R. BRITO et al. Balancing MMPs in chronic wounds: a pilot study with Dermax. Abstract Dutch Association for Plastic Surgery, Aalst, Belgium, 2002 Nov 23

4. A. B. WYSOCKI, L. STAIANO-COICO and F. GRINNELL, J. Invest. Dermatol. 101(1) (1993) 64

5. D. R. YAGER, L. Y. ZHANG, H. X. LIANG, R. F. DIEGELMANN and I. K. COHEN, J. Invest. Dermatol. 107(5) (1996) 743

6. M. WECKROTH, A. VAHERI, J. LAUHARANTA, T. SORSA and Y. T. KANTTINEN, J. Invest. Dermatol. 106 (1996) 1119

7. M. VAALAMO, M. WECKROTH, P. PUOLAKKAINEN et al., Br. J. Dermatol. 135(1) (1996) 52

8. N. J. TRENGOVE, M. C. STACEY, S. MACAULEY et al., Wound Repair Regen. 7 (1999) 442

9. E. C. BULlEN, M. T. LONGAKER, D. L. UPDIKE et al., J. Invest. Dermatol. 104(2) (1995) 236

10. S. J. WALL, M. J. SAMPSON, N. LEVELL and G. MURPHY, Br. J. Dermatol. 149(1) (2003) 13

11. R. F. GERLACH, A. P. DE SOUZA, J. A. CURY and S. R. P. LINE, Eur. J. Oral Sci. 108 (2000) 327

12. R. MYLLYLA, H. ANTINNEN and K. I. KIVIRIKKO, Eur. J. Biochem. 101(1) (1979) 261

13. D. K. PERRY, M. J. SMYTH, H. R. STENNICKE et al., J. Biol. Chem. 272(30) (1997) 18530
14. S. K. MALLYA and H. E. VAN WART, J. Biol. Chem. 264(3) (1989) 1594

15. Z. Y. ZHANG, I. M. REARDON, J. O. HUI et al., Biochemistry 30(36) (1991) 8717

16. Y. HOJIMA, B. BEHTA, A. M. ROMANIC and D. J. PROCKOP, Matrix Biol. 14(2) (1994) 113

17. A. P. SOUZA, R. F. GERLACH and S. R. P. LINE, Dent Mater. 16 (2000) 103

18. Q. TAN, Z. LIN, W. MA et al., Burns 28 (2002) 443

19. D. P. VOOIJS, X. F. WALBOOMERS, J. A. PARKER, J. W. VON DEN HOFF and J. A. JANSEN, J. Biomed. Mater. Res. 70A(3) (2004) 402

20. A. M. RASIK, R. RAGHUBIR, A. GUPTA et al., J. Ethnopharmacol. 68(1-3) (1999) 261

21. G. MAWERA, D. MUTSEEKWA, N. NYAZEMA and S. A. ASALA, East Afr. Med. J. 74(8) (1997) 495

22. K. S. STENN and S. P. YAN, Biomater. Med. Devices Artif. Organs 13(1-2) (1985) 17

23. E. B. CABBABE and S. W. KOROCK, Ann. Plast. Surg. 17(4) (1986) 330

24. B. ARBOLEDA and N. I. CRUZ, Plast. Reconstr. Surg. 83(1) (1989) 118

25. M. F. JONKMAN, P. BRUIN, E. A. HOEKSMA et al., Surgery 104(3) (1988) 537

26. T. P. SUlliVAN, W. H. EAGLSTEIN, S. C. DAVIS and P. MERTZ, Wound Repair Regen. 9 (2001) 66

27. J. GROSS, W. FARINELLI, P. SADOW, R. ANDERSON and R. BRUNS, Proc. Natl. Acad. Sci. USA 92(13) (1995) 5982

28. J. M. DAVIDSON, Wounds 13(1) (2001) 9 (http://www.medscape.com/viewarticle/407568)

29. J. A. PARKER, X. F. WALBOOMERS, J. W. VON DE HOFF, J. C. MALTHA and J. A. JANSEN, Tissue Eng. 8(5) (2002) 853

30. M. S. AGREN, U. MIRASTSHIJSKI, T. KARSMARK and U. K. SAARIALHO-KERE, Exp. Dermatol. 10 (2001) 337

31. A. J. VAN DEN BERG, S. B. HALKES, H. C. van UFFORD, M. J. HOEKSTRA and C. J. BEUKELMAN, J. Wound Care 12(10) (2003) 413 